https://doi.org/10.46344/JBINO.2021.v010i01.34

\title{
ASSESSMENT OF KNOWLEDGE AND ATTITUDE TOWARDS MENTAL ILLNESS AMONG COLLEGE OF HEALTH AND MEDICAL SCIENCE STUDENTS
}

\author{
Bahubali J Geddugol', Yayathee Subbarayalu', Sreevani $\mathbf{R}^{2}$ \\ 1. Shri Venkateshwara University, Rajpur, Gajaroula, (UP) India. \\ 2. Dharwad Institute of Mental Health and Neuroscience Dharwad, India.
}

\section{Email ID: bahu007@gmail.com}

\begin{abstract}
Background: Although the interest and knowledge of physical diseases among medical students are much higher than mental illness, it's prevalent that the knowledge about mental disorders has been comparatively neglected and ignored due to underestimation and poor attitude. There has been ignorance of the mental health aspect of overall health maintenance; which leads to an increase in the rate of illness and burden on the mentally ill individual, family and country as a whole. Objectives: To assess knowledge and attitude towards mental illness among Health and Medical Science Student studying in Dr. J. J Magdum Trust. Methods: Institutional based cross-sectional study was conducted scheduled from February 25thto March $7^{\text {th }} 2017$ at Dr. J J Magdum trust's Homeopathy, Ayurvedic and Nursing College Jaysingpur, Maharashtra. The tool used was a structured questionnaire and administered to 483 participants. The samples were calculated and selected by multi-stage sampling procedure and simple random sampling technique. The questionnaires include the basic demographic information, opinions about potential knowledge and attitude among health and medical science student towards mental illness. The descriptive and inferential data were analyzed with the help of SPSS version 20 software program. Result: All of the respondents (100\%) had general information about mental illness. And $30.4 \%$ of samples had information from media. About $27.3 \%$ From magazine, $5.4 \%$ got it from friends and relatives, $5.6 \%$ from others like religious institutions, As well as nearly half of the respondents, have a good attitude toward mental illnessConclusion: All of our respondents had good knowledge but nearly half of respondent have a poor attitude towards mental illness.
\end{abstract}

Keywords: Knowledge, Attitude, Mental Illness, Medical Science Students. 


\section{BACKGROUND INFORMATION}

Mental disorders are widely recognized major contributor (14\%) to the global burden of disease worldwide, for instance, the data according to World Health Organization reported that in 2005, 154 million people globally suffered from depression, 25 million people suffered from schizophrenia, 91 million people from alcohol used disorder and 15 million from drug used disorder (WHO, 2004).

Nearly $25 \%$ of individuals in both developed and developing countries develop one or more mental or behavioral disorders at some stage in their life (WHO, 2001). Above data signifies the total population suffering from mental disorders is accountable to the societal burden. And hence, the rejection and isolation is the commonest tendency of public of society and patients themselves (self-rejection and self-isolation) due to inability in a significant contribution to the society and country at large.

Although some countries around the world have managed to fight the stigma and increasing acceptance of the mentally ill, still there is a gap in understanding the mental illness and the patients; for instance lack of awareness is very evident in India and other developed countries. Mentally ill people are labelled as different from other people and are viewed negatively by others. Many other studies have demonstrated that persons labelled as mentally ill are perceived with more negative attributes and are more likely to be rejected regardless of their behaviours Arkarh, Ekar D 2000). Stigma remains a powerful negative attribute in all social relations. It is considered an amalgamation of three related problems: lack of knowledge (ignorance), negative attitude (prejudice) and exclusion or avoidance behavior (discrimination). As per the researchers understanding, in olden days; these amalgamated problems were well prevalent associated with tuberculosis, leprosy and other medical illnesses; as the medical science advanced and invented the appropriate treatment against the infection. Simultaneously, the stigma and prejudice associated with the infection was diminished in the influence of better understanding and rationalized facts. But, with regards to the person with mental illness it's not so; perhaps due to lack of treatment modalities to cure completely and invisible signs and symptoms of illness projects as purposeful and intentional/ faking of symptoms thus, it creates dilemma and controversies in understanding the basic psychopathology to the society.

The study reported that, people who are labelled as mentally ill associated themselves with society's negative conceptions of mental illness and that societies negative reactions contribute to the incidence of mental disorder. The social rejection results from these many handicaps mentally ill people even further (Scheff TJ1999).

A persistent negative attitude and social rejection of people with mental illness have prevailed throughout history in every social and religious culture. Of all the health problems, mental illness are poorly 
understood even by the health and medical science students. Such as poor knowledge and negative attitude towards mental illness threatened the effectiveness of patient care and rehabilitation. This poor and inappropriate view about mental illness and negative attitude towards mental illness can inhibit the decision to seek help and provide holistic care. Better knowledge is often reported to result in an improved attitude towards people with mental illness and a belief that mental illness is treatable can encourage early treatment-seeking and promote better outcome (Stuart H 2000).

In India, $7.5 \%$ of population is affected by some or other form of mental health problems; of which $1.9 \%$ have severe forms of mental disorder (NIMHANS, 2016). A problem is aggravated by poverty, unemployment and the presence of physical illness like HIV/AIDS. These are known risk factors for common mental health problems (Oxford University 1999). There is a serious social stigma attached to mental disorders but the burden is likely to have underestimated because of inadequate appreciation of the connectedness between mental illness and other health conditions (Bedrihan $T$ 1999). Discrimination and social exclusion related to mental illness are recognized as a major public health concern (WHO 2001).

In India, there is a widespread belief that severe mental illness is due to demon possession, bewitchment by the evil spirit, ancestor's spirits or the evil eye has existed for many years, this influence the attitude towards mental illness and practice associated with mental health problems.
With the researchers observation majority of Indian population in India use traditional healing methods for treating mental illness and those who look for modern treatment do so having tried and failed several local means.

After having tried and failed the available local means, many families keep the patient at home under restraint until they are no longer aggressive and violent once the disruptive behavior is over they will be realized from the chain and many of them become wanderers and homeless (Alem A,Desta M,Araya M).

Efforts to improve society's' knowledge of mental disorder have been much less common than for cancer and heart disease, nevertheless, several approaches have been tried; one is information campaign targeted at the general population the campaign showed some change in the knowledge and belief of the society about mental illness and help to seek (Paykl E. S, Hart.D, Priest RG, 1998).

There are also attempt to improve the quality of information presented in the media through expert input but there is no research on the effects of involving mental health professionals in the media (Ester LG, Cooker PG \&lttenbach1998, Shibire T 2002) Despite the increased burden of mental health problems little known about knowledge and attitude of the health and medical science students toward mental health problems. Understanding the attitude of these students towards mental illness could help target initiatives to reduce stigma and enhance the utilization of mental health service. Therefore, the result of these study will be used as a baseline data for planning to improve o.com I Innovative Association
o 
knowledge and, attitude towards mental illness.

\section{SIGNIFICANCE OF THE STUDY}

The finding from this study will enable the researchers to know the knowledge and attitude of the students towards Mental illness. Such information provides crucial support for increase the awareness on the prevalence of knowledge, and attitude towards mental illness among health and medical science students and also may be used as baseline information for those who want to do their research on this related topic, may aid to develop strategies for improvement of knowledge and attitude towards mental illness.

\section{Conceptual Framework}

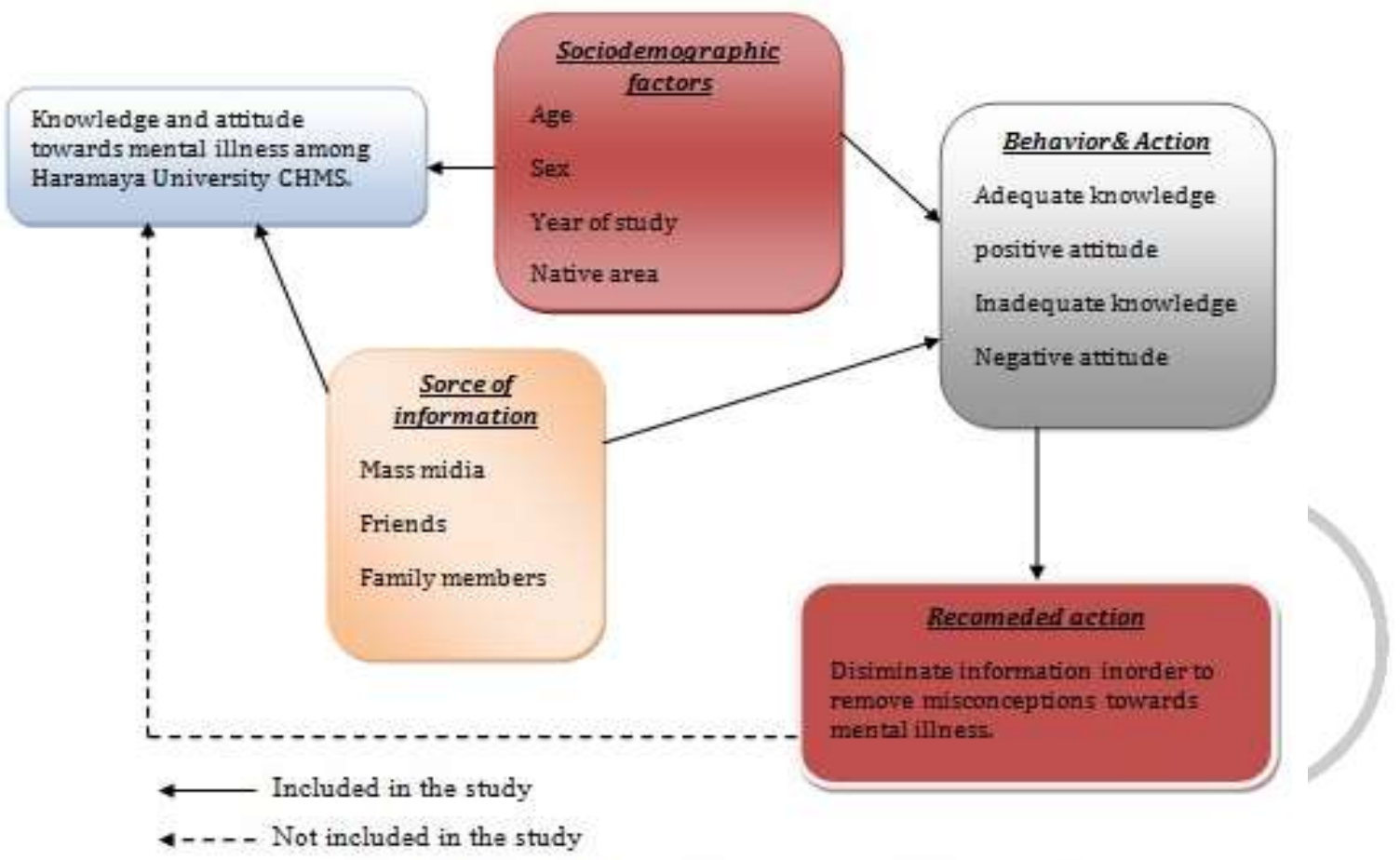

Figure 1:Schematic presentation of conceptual framework

\section{MATERIAL \& METHODS}

Institutional based cross-sectional study design was adopted. The source population consisting of all students studying Homeopathy, Ayurvedic and Nursing courses under Dr. J. J Magdum Trust's and the study samples were selected by excluding the students who are severely ill and absent at the time of data collection. Multistage stratified simple random sampling technique was used to select the samples for the study. The total 483 samples were included based on the population proportion formula. The data was collected by self-administration of a structured questionnaire which was designed and modified appropriately. The collected data was processed by using SPSS version 20 consisting of descriptive and inferential analysis, table, figure, frequency, percentages, and crosstabulation. Finally, the finding of the study was summarized, presented, discussed based on the nature of questions. The letter of ethical clearance was obtained from the Institutional Ethics committee Dr. 
J. J Magdum Trust's College of Nursing, Jaysingpur.

\section{RESULT}

Assessments of Socio-demographic characteristics

The responses of 483 students were analyzed. A total of 310 (64.08\%) were male, while $173(35.02 \%)$ were female. The ages of students ranged from 18 and 32 years. The majority of the students 209 (43.3\%) were between the age of 21 and $23,130(26.9 \%)$ were between the age of 24 and 26 years, while 115 (23.8\%) were

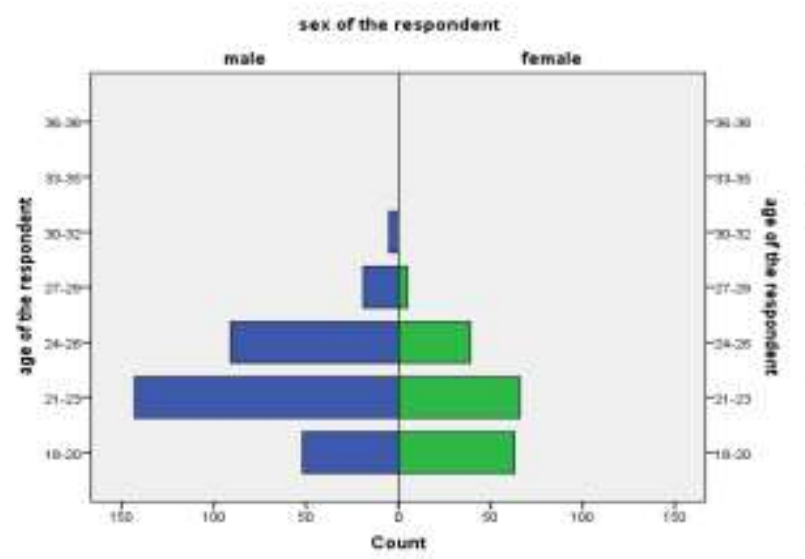

FIGURE 1:SEX AND AGE OF THE RESPONDENT between 18 and 20 years of age. Twenty four (5\%) were between 27 and 29 and 5 (1\%) were between 30 and 32 years. About $363(75.1 \%)$ were from Maharashtra, 232(48\%), 51 (10.6\%) were from Karnataka, 69 (14.3\%) and rest of India. Majority 407 (84\%) were Hindu, and 76 (15.6\%) were Muslim. Ninety $(18.6 \%)$ were the first year, $84(17.7 \%)$ were the second year, $94(19.5 \%)$ were the third year, $111(23 \%)$ were the fourth year, 104 (21.6\%) were the fifth year students in respective branch of study.
Assessment of Knowledge regarding Mental Illness among Students

After the responses of all respondents were computed using the whole

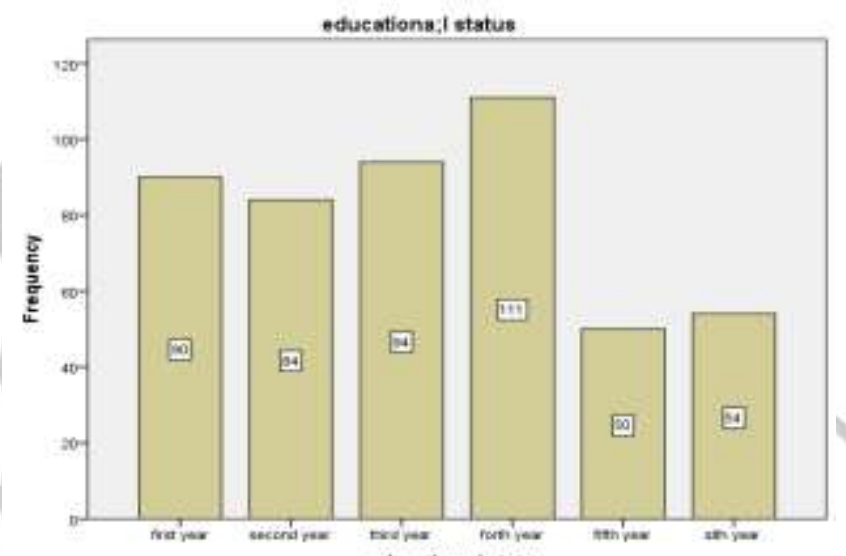

FIGURE 2:EDUCATIONAL STAT STS ABOUT THE STUDENT knowledge questionnaire 462(95.7\%) had good knowledge, while $21(4.3 \%)$ had poor knowledge about mental illness.

TABLE 1: OVERALL KNOWLEDGE OF STUDENTS REGARDING MENTAL ILLNESS

\begin{tabular}{llc} 
& & $\mathbf{N}=\mathbf{4 8 3}$ \\
\hline Variable & Frequency & Percent \\
\hline Good knowledge & 462 & 95.7
\end{tabular}

Poor knowledge

21

4.3

\section{Total}

483

100 


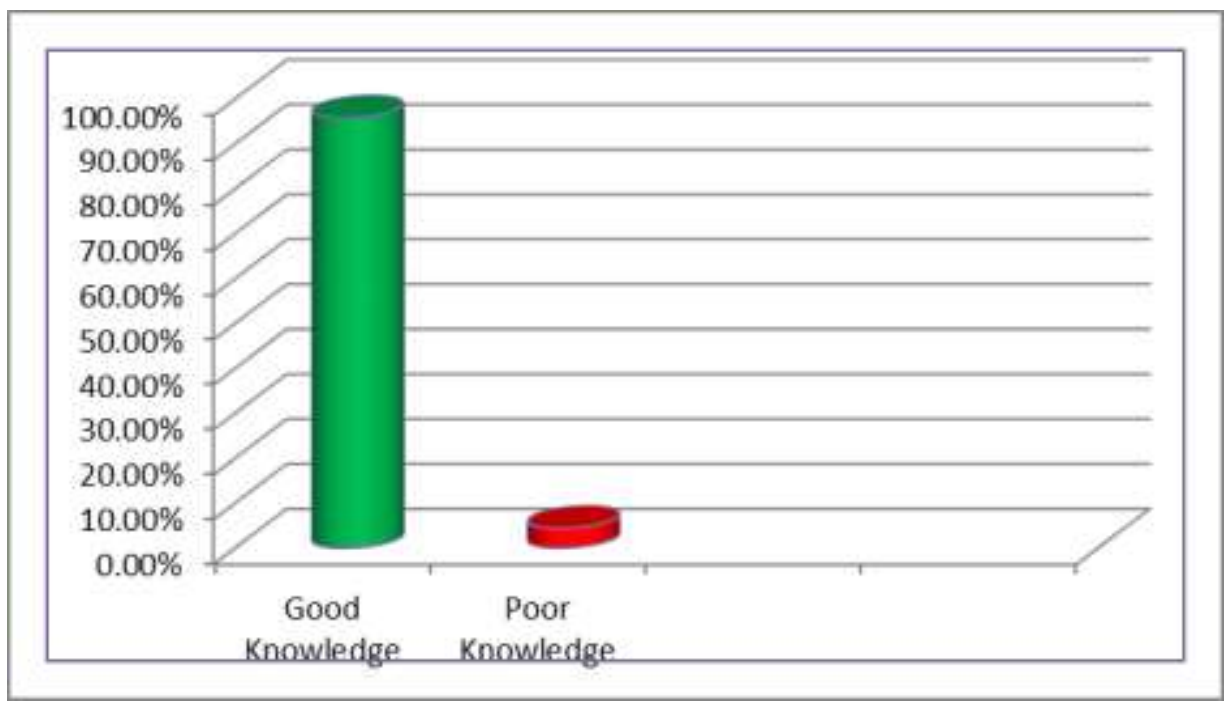

\section{FIGURE 5: Overall knowledge of students regarding mental illness}

When students were asked about their knowledge of mental illness and the source of their information all students $483(100 \%)$ had ever heard about mental illness. Respondents heard information about mental illness. And $30.4 \%$ of samples had information from media. About 27.3\% from magazine, $5.4 \%$ got it from friends and relatives, $5.6 \%$ from others like religious institutions

Table2: Students were asked what they think caused the mental illness $(\mathrm{N}=483)$

\begin{tabular}{|c|c|c|c|c|c|}
\hline \multirow[t]{2}{*}{ No } & \multirow[t]{2}{*}{ Variables } & \multicolumn{2}{|l|}{ Yes } & \multicolumn{2}{|l|}{ No } \\
\hline & & Frequency & $\%$ & Frequency & $\%$ \\
\hline & $\begin{array}{l}\text { Substance misuses like alcohol or drug } \\
\text { cause mental illness }\end{array}$ & 452 & 93.6 & & 6.4 \\
\hline 2 & $\begin{array}{l}\text { Genetic inheritance may because of mental } \\
\text { illness }\end{array}$ & 406 & 84.1 & 77 & 15.9 \\
\hline 3 & A head injury can because mental illness & 442 & 91.5 & 41 & 8.5 \\
\hline 4 & Stress in daily life leads to mental illness & 452 & 93.6 & 31 & 6.4 \\
\hline 5 & $\begin{array}{l}\text { Physical illness like ( diabetes HIV ) can } \\
\text { cause mental illness }\end{array}$ & 378 & 78.3 & 105 & 21.7 \\
\hline 6 & $\begin{array}{l}\text { Mental illness caused by punishment form } \\
\text { god }\end{array}$ & 114 & 23.6 & 369 & 76.4 \\
\hline 7 & $\begin{array}{l}\text { Evil spirit can be the cause of mental } \\
\text { (illness ) }\end{array}$ & 289 & 59.8 & 194 & 40.2 \\
\hline 8 & Mental illness is curable & 363 & 75.2 & 120 & 24.8 \\
\hline
\end{tabular}


9 Mental illness is contagious

171

10 People with mental illness successfully 388 treated with me dictation

11 People with mental illness successfully 403 treated by discussing with health professionals

12 Psychiatric medication will cause 338 addiction
$35.4 \quad 312 \quad 64.6$

$\begin{array}{lll}80.3 & 95 & 19.7\end{array}$

$83.4 \quad 80$

16.6

$70 \quad 145$

30

\section{ASSESSMENT OF STUDENTS REGARDING MENTAL ILLNESS}

Generally, after the responses of all respondents were computed using the whole attitude questionnaires $259(53.6 \%)$ of the respondents had a positive attitude towards mental illness while $224(46.4 \%)$ of them had negative attitude regarding mental illness.

TABLE3: Overall assessment of student's attitude regarding mental illness $\mathrm{N}=483$

\begin{tabular}{lcc}
\hline Variable & frequency & Percent \\
\hline Good attitude & 259 & 53.6 \\
Poor attitude & 224 & 46.4 \\
\hline Total & $\mathbf{4 8 3}$ & $\mathbf{1 0 0}$ \\
\hline
\end{tabular}

\section{Figure 6:}

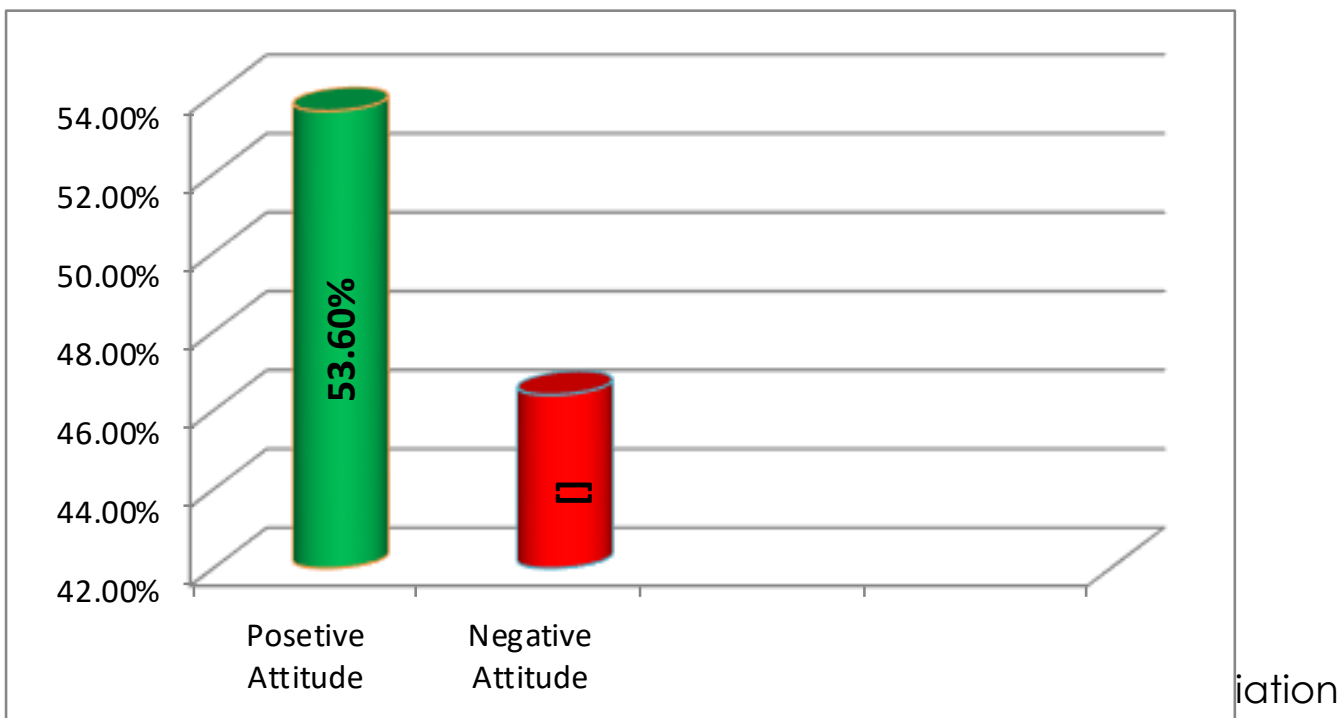


Overall assessment of student's attitude regarding mental illness

Correlation between knowledge and attitude among student

Findings of the present study revealed that the student's overall knowledge and attitude scores ' $r$ ' valuewas (0.244), thus there was a positive correlation between knowledge and attitude among rural adults.

TABLE 1: Correlation between knowledge and attitude among student $(\mathrm{N}=\mathbf{4 8 3})$

\begin{tabular}{cccc}
\hline Group & Between & "r" value & Interference \\
\hline Students & $\begin{array}{c}\text { Overall knowledge } \\
\text { and attitude }\end{array}$ & 0.244 & Positive attitude \\
& & & \\
\hline
\end{tabular}

\section{DISCUSSION}

According to our study, the sign and symptom of mental illness were, Talking alone (93.8\%), aggression (88.2\%) laughing alone $(91.90 \%)$, sleep disturbance (88\%) and self-neglect $(87 \%)$ were sign and symptoms described by our participants, According to a study conducted in Agaro town of Ethiopia, on how mental health problems are perceived by the community, there was about $99.5 \%$ respondent rate in which a total of 728 people were interviewed. As this study showed, talking to oneself, strange behavior, sleep disturbance and aggression were the most common perceived symptoms of mental illness. The concurrency of discrepancy may be the difference between sample size and study area.

According to Our study, the cause of the mental illness was Substance misuses like alcohol or drug $452(93.6 \%)$, the stress in daily life 452 (93.6\%) and head injury 442 (91.5\%), evil spirit $289(59.8 \%)$, physical illness 378(78.3\%). God punishment 114(23.6\%), the research that conducted in Malawi with a total of 210 participants showed that about $95 \%$ of respondents were attributed mental disorder to alcohol and illicit drug abuse. It is followed by $92.8 \%$ (brain disease), $82.8 \%$ (sprit possession) and $76.1 \%$ (psychological trauma).The occurrence of little discrepancy $b / n$ these study may be study area.

According to Our study, the cause the mental illness was Substance misuse like alcohol or drug 452 (93.6\%), the stress in daily life 452 (93.6\%) and head injury 442 (91.5\%), evil spirit $289(59.8 \%)$, physical illness 378(78.3\%). God punishment 114(23.6\%), another study conducted in Nigerian University Most respondents were given 
more than one possible answers. About $82.7 \%$ of respondents were believed traumatic life events as the cause of mental illness, out of these respondents, which craft 95.2\%), possession by an evil spirit (44.2\%) and punishment from God (30\%) are causes of mantel illness.

The majority of study participants 154 $(31.9 \%)$ agreed with the statement that people with mental illness are dangerous. This finding is lower than the findings from Nigeria, which was $96.5 \%$; this variation may be attributed to the study setting and the sample size. The samples of $38.3 \%$ of the respondents agreed that people with mental illness can work in regular jobs. This is higher in proportion when compared to the study carried out in Nigeria which indicated that only $(16.9 \%)$ of the respondents thought that people with mental illness can work in regular jobs. This variation may be explained by differences in the study setting and the populations. (38.5\%) agreed with the statement that afraid to have a conversation with someone with mental illness. These are lower when compared to study conduct in Nigeria which showed a higher proportion of respondents (82.7\%) would afraid to have a conversation and would be disturbed to work with a person who has a mental illness. This variation may be explained by differences in the study setting and the population. From our study result (40\%) of respondents agreed with the statement that one can marry with a person having a mental illness. This is higher in percentage when compared to study carried out in Nigeria which showed that (3.4\%) of the respondents still would consider marrying a person having a mental illness. the reason for this discrepancy may different in study seating and different population.

According to our study the correlation $\mathrm{b} / \mathrm{h}$ knowledge and attitude of our respondents were positive, the correlation score is that(0.224); according to the research that done in India among 200 college students about knowledge and attitude of the students toward mental illness were found to significant positive correlation has been found between the attitude\& knowledge score $(p=0.01)$.

\section{CONCLUSION}

All our respondents 483 (100\%) had ever heard about mental illness. Most of the respondents got information about mental problem through media, magazine, institution, friends and relatives. Regarding students' knowledge and attitude, a total of $95.7 \%$ and $53.4 \%$ had good knowledge and attitude toward mental illness respectively. According to this study the correlation between knowledge and attitude show that nearly half of respondents have good knowledge, but they have poor attitude toward mental illness. This indicates the need for increasing students' knowledge on characteristics of mental illness.

\section{REFERENCES}

- Alem A, Desta M and Araya M.1999 Mental health in Ethiopia, Ethiopian journal of health development;9:47-62 
- Arkar H, Ekar D.2000, Effects of psychiatric labeled on attitude towards mental illness in a Turkish sample. IntJsoc psychiatry.;40:205-213

- Bedrihan T;1999, The global burden of mental disorders, American journal of public health, 89(9)

- Bhugra D, Leff J,2001 Attitude towards mental illness in: (Bhugra $D$ and Leff j) principles of social psychiatry, blanked scientific published ;385-399.

- Bishaw M1999.promoting traditional medicine in Ethiopia; soc sic med;33,193200Br J 2000 psychiatry. 177:396-401

- CDC 2010.Attitude towards mental illness35 states, district of Colombia and Puerto Riko; CDC weekly59(20);619-625

- Desjardins R, Eisenburg L: A 1999, world mental health problem and properties in low income countries; oxford University press, oxford Inc,

- Diribew A.2005, Awareness and attitude towards common mental health problems, Agaro town south western Ethiopia; Ethiopian journal of health sci.15(1) 1-21

- DM Ndetei1,2, LI Khasakhala1,2, V Mutiso2, AW Mbwayo2 ,2011,nowledge, attitude and practice (KAP) of mental illness among staff in general medical facilities in Kenya: practice and policy implications

- Esters. L.G., Cooker P.G. \&lttenbach R.F. 1998, Effects of a unit of instruction in mental health on rural adolescents conceptions of mental illness and attitude about seeking help. Adolescence. 33;469476.

- F. Olatunji. Aina l, F. Tajudeen Suleiman, O. Yewande Oshodil andDerin O. Olorunshola 2009, Medical students' beliefs about treatment and rehabilitation of persons with mental illness.

- Gururaj G, Varghese M, Benegal V, Rao GN, Pathak K, Singh LK, et al. National Mental Health Survey of India, 2015-16: Summary. Bengaluru, National Institute of Mental Health and Neuro Sciences, NIMHANS Publication No. 128, 2016.

- Johannessen ,J.O. 1998,Early intervition and prevention in schizophrenia: experiences from a study in Stavanger, Norway, seishinshinkeigakuzasshi. Psychiatrica et neurologia japonica, 100;511-522.

- Jorm AF. Mental health literacy: public knowledge and belief about mental disorders

- ,Jugal K, Mukherjee R, Parashar M, Jiloha RC, Ingle GK.2007Beliefs and attitudes towards mental health among medical professionalism Delhi. Indian J Community Med.;32:198-200.

- Kleiman A, 2002,Rethinking psychiatry from cultural category to personal experience. New York : free press.

- Lauder C, Anthony M, Ajdacis-Gross V, Rossler W.2004 What about Psychiatrists' attitude towards mentally ill people. European Psychiatry W. ; 19(7): 423-427. 
- ,Lauder C, Nordt C, Falcato L, Rossler W. 2006Volunteering in Psychiatry: Determining factors of attitude and actual Commitment. Psychiatry Prax 27:347350

- Mesfin A, Aboud F 2000;mental illness in Ethiopia, in kloos H. zeinAz(eds); the ecology of health and disease in Ethiopia, 493-506

- Mr. Ganesh k,2002 knowledge and attitude of mental illness among general public of southern India.

- Raguran R., Ragu, TM, Vounatsou P, Weiss MG.2004 Schizophrenia and the cultural epidemiology of stigma in Bangare, India. J NervMent Dis ; 192:734-744.

- Samuel M.1999, perception of mental and physical illness in north western Ethiopia, causes, treatment, and attitude. J health Psychol;4:531-549

- Scheff TJ,1999 Being mentally ill: a sociological theory. Chicago, IL. Aldine;
- Tekle-Haimanot R, Forsgren L, Gebremariam A etal 1991,.Attitude of rural people in central Ethiopia towards Epilepsy. SocSci Med, ; 32(2): 203-209.

- WHO, 2004, world mental health survey consortium, prevalence, severity, and unmet need for treatment of mental disorders in the world health organization world mental health survey. JAMA.;291:20581-2590

- WHO, 1999 mental health care in developing countries; a critical appraisal findings, technical report series 698, WHO, Geneva.

- World bank, 1999 development report inventory on health, oxford University press, new York. 